\title{
El alineamiento en seguridad internacional de los países de la Alianza del Pacífico con Estados Unidos: una aproximación desde el realismo constructivista
}

\author{
Javier ERNESTO RamíreZ BullóN* \\ Alexandra PÉREZ JimÉneZ** \\ REYNELL BADILLO SARMIENTO***
}

Artículo recibido: 12 de mayo de 2020

Artículo aprobado: 8 de febrero de 2021

Doi: https://doi.org/10.12804/revistas.urosario.edu.co/desafios/a.9042

Para citar este artículo: Ramírez Bullón, J. E., Pérez Jiménez, A., \& Badillo Sarmiento, R. (2021). El alineamiento en seguridad internacional de los países de la Alianza del Pacífico con Estados Unidos: una aproximación desde el realismo constructivista. Desafíos, 33(1), 1-40. https://doi.org/10.12804/revistas.urosario.edu.co/desafios/a.9042

\section{Resumen}

Los estudios de regionalismo han desestimado indagaciones que analicen la Alianza del Pacifico (AP) en el ámbito de la seguridad. Este artículo busca comprender el rol de las ideas de seguridad en el grado de alineamiento de las políticas exteriores de los paises de la AP con Estados Unidos (EE. UU.). Esta investigación emplea una

\footnotetext{
* Pontificia Universidad Católica del Perú (PUCP) (Lima, Perú). Correo electrónico: jramirezb@pucp.edu.pe. ORCID: orcid.org/0000-0001-5594-8307

** Universidad de los Andes (Bogotá, Colombia). Correo electrónico: ac.perezj@uniandes. edu.co. ORCID: orcid.org/0000-0002-3576-8533

*** Universidad del Norte (Barranquilla, Colombia).Correo electrónico: ra.badillo@uniandes.edu.co. ORCID: orcid.org/0000-0003-2816-742X
} 


\title{
2 I Javier Ernesto Ramírez Bullón - Alexandra Pérez Jiménez - Reynell Badillo Sarmiento
}

perspectiva ecléctica que combina aportes del constructivismo y del realismo y aplica una metodología cualitativa que complementa el rastreo de procesos históricos con el análisis temático de discursos presidenciales y libros blancos de defensa. Los hallazgos sugieren que los miembros de la AP han demarcado un patrón común de conducta frente a las acciones en materia de seguridad internacional propuestas por Washington en el Consejo de Seguridad de las Naciones Unidas (ONU). Entre los factores que explican este comportamiento se encuentran trayectorias dependientes de cooperación en seguridad con EE. UU. y nociones compartidas de amenaza internacional.

Palabras clave: alineamiento; política exterior; Alianza del Pacífico; Estados Unidos; seguridad internacional; regionalismo; eclecticismo.

\section{The International Security Alignment of Pacific Alliance's Members with the United States: A Constructivist Realist Approach}

\begin{abstract}
Studies of regionalism have usually dismissed inquiries into the implications of the Pacific Alliance (PA) for the field of security. This article seeks to understand the role of security ideas in the degree of alignment of $P A$ countries' foreign policies with the United States (USA). Our approach combines contributions from constructivism and realism. This research applies a qualitative methodology that relies on process tracing along with thematic analysis of presidential speeches and defense white papers. The findings suggest that PA members have a common pattern of behavior in the face of international security actions prompted by Washington in the UN Security Council. We show that this foreign policy behavior is explained by path dependent trajectories of security cooperation with the USA and shared notions of international threat.
\end{abstract}

Keywords: Alignment; foreign policy; Pacific Alliance; United States; international security; regionalism. 


\title{
O alinhamento da segurança internacional dos países da Aliança do Pacífico com os Estados Unidos: uma abordagem a partir do realismo construtivista
}

\begin{abstract}
Resumo
Os estudos de regionalismo têm dispensado investigações que analisam a Aliança do Pacifico (AP) no campo da segurança. Este artigo busca compreender o papel das ideias de segurança no grau de alinhamento das politicas externas dos paises membros da AP com os Estados Unidos. Esta pesquisa emprega uma perspectiva eclética que combina contribuições do construtivismo e do realismo e aplica uma metodologia qualitativa que complementa o rastreamento de processos históricos através da análise temática de discursos presidenciais e livros brancos de defesa. Os resultados sugerem que os membros da AP demarcaram um padrão comum de conduta em relação às ações de segurança internacional propostas por Washington no Conselho de Segurança das Nações Unidas. Entre os fatores que explicam esse comportamento estão as trajetórias dependentes de cooperação em segurança com os Estados Unidos e as noções compartilhadas de ameaça internacional.
\end{abstract}

Palavras-chave: alinhamento; politica externa; Aliança do Pacifico; Estados Unidos; segurança internacional; regionalismo; ecletismo.

\section{Introducción}

Los países de la Alianza del Pacífico (AP) tienen estrechos lazos de cooperación con Estados Unidos (EE. UU.) que los diferencian del resto de países latinoamericanos (Ardila, 2015; Nolte \& Wehner, 2013; Olano Alor, 2017). En efecto, durante inicios del siglo XXI, Chile, Colombia, México y Perú se apartaron de la crítica regional a la hegemonía estadounidense. Mientras ascendían proyectos "posthegemónicos" como la Unión de Naciones Suramericanas (Unasur) o la Alternativa Bolivariana para América Latina y el Caribe (ALBA), la AP se fundó según ideas como el libre comercio y la democracia liberal, las cuales convergían con el orden internacional liberal que promovía EE. UU. (Ikenberry, 2010; Riggirozzi \& Tussie, 2012; Sanahuja, 2016). 


\section{4 / Javier Ernesto Ramírez Bullón - Alexandra Pérez Jiménez - Reynell Badillo Sarmiento}

Es decir, precisamente cuando se relanzaba el ideal de autonomía en la política exterior latinoamericana (Mijares, 2020), los países de la AP reafirmaron su alineamiento con los valores que proyectaba el hegemón.

Si bien la literatura académica ha examinado el papel de las ideas económicas y políticas en el surgimiento y orientación de la AP, existe una omisión sobre cuán relevantes fueron las visiones compartidas de seguridad internacional (Marchini 2019; Pastrana Buelvas \& Castro, 2019; 2020; Vargas Alzate 2019). Además, tampoco se ha explorado empíricamente en qué medida la convergencia ideológica de los cuatro países de la AP reproduce un alineamiento colectivo de política exterior con EE. UU. (Pastrana \& Gehring, 2014). En el fondo, estos vacíos en la literatura se mantienen porque se tiende a asumir dos premisas: 1) resulta innecesario estudiar la AP desde un enfoque de seguridad internacional porque carece de políticas de defensa común, y 2) el alineamiento de las políticas exteriores de Colombia, Chile, México y Perú con EE. UU. no refleja un alineamiento conjunto, sino bilateral. Ambas presunciones merecen ser analizadas críticamente.

Pese a que la AP se cimentó explícitamente en ideas económicas, esto no quiere decir que las ideas compartidas de seguridad se encuentren por fuera de los catalizadores ideológicos que constituyeron una identidad regional entre los cuatro países. De hecho, al tener una relación tan estrecha con EE. UU. se esperaría que los países de la AP no solo hayan interiorizado ideas y prácticas afines al libre comercio, sino también nociones compartidas de amenazas internacionales. Esta convergencia ideológica representa un aspecto desestimado en los análisis, debido a la división entre los estudios de seguridad y regionalismo. Sin embargo, desde una perspectiva integral, es necesario explorar cómo diferentes ideas cambian el alineamiento de política exterior con la potencia hegemónica. Por otro lado, existen pocas investigaciones que evalúen en qué medida los países de la AP tienen patrones de política exterior comunes frente a EE. UU. (Ayala Castiblanco \& Ramírez Bullón, 2017). En consecuencia, debemos esclarecer si el alineamiento ideológico en temas de seguridad, al interior de cada país de la AP, genera un comportamiento colectivo que los diferencie de otros bloques regionales. En consecuencia, el 
objetivo principal de esta investigación es analizar el rol de las ideas de seguridad sobre el grado de alineación de las políticas exteriores de los países de la AP con EE. UU.

Encontramos que la pertenencia a la AP está correlacionada con una posición común frente a temas de seguridad internacional. En esta línea, sostenemos que la identidad regional de los países de la AP no solo se fundamenta en nociones compartidas de economía, sino además en ideas de seguridad comunes. A su vez, afirmamos que los países de la AP respaldan de manera conjunta las acciones propuestas por Washington en el Consejo de Seguridad y la Asamblea General de las Naciones Unidas (ONU) no solo durante las coyunturas observadas, sino también como un rasgo consistente de su política exterior. Dicho comportamiento constata una alineación particular que no se encuentra en otros países latinoamericanos, como los miembros del Mercosur. Tal convergencia ideológica está inspirada en conceptos difundidos por EE. UU., como la securitización de la política antidrogas, pero también se sustenta en componentes materiales. Con todo, EE. UU. privilegia la asistencia de defensa hacia los países de la AP en comparación con el resto de los países latinoamericanos. En consecuencia, nuestro argumento central es que la AP intercambia un alineamiento colectivo con EE. UU. a cambio de obtener beneficios en el plano de la cooperación en seguridad, debido a la confluencia de ideas con el hegemón en ese campo.

Ahora bien, no intentamos explicar el surgimiento de esta actitud bajo la dicotomía autonomía-dependencia ni tampoco desde visiones estructurales (Friedman \& Long, 2015; Russell \& Tokatlian, 2013). En cambio, proponemos una explicación ecléctica que considera las trayectorias históricas de alineación que ocurrieron al interior de los Estados. En este sentido, durante coyunturas críticas, los cuatro países de la AP decidieron interiorizar concepciones y prácticas de seguridad afines a EE. UU., en función de sus intereses propios, como la lucha contra amenazas internas. Consideramos, por lo tanto, que la alineación de estos países es más que una simple imposición ideológica o material: es el resultado de una interacción de ambos elementos. Si bien encontramos actitudes de aquiescencia, también resaltamos que 


\section{6 / Javier Ernesto Ramírez Bullón - Alexandra Pérez Jiménez - Reynell Badillo Sarmiento}

hubo concesiones en materia de seguridad provistas por la potencia hegemónica. Por lo tanto, el alineamiento se basa en cuotas de satisfacción otorgadas por el hegemón.

\section{Realismo constructivista: una perspectiva ecléctica}

En esta investigación nos interesa examinar los aspectos ideológicos de la alineación en política exterior. Además, consideramos relevante analizar factores internos como los discursos y prácticas de las élites de política exterior (EPE) respecto a la hegemonía estadounidense. Una inspección preliminar de las teorías disponibles nos inclina a elegir un punto de vista reflectivista, como el constructivismo en su versión no sistémica. Sin embargo, dicha perspectiva pocas veces se utiliza para examinar la política exterior, menos aún para el caso de países latinoamericanos (Becerra, 2013). Por otro lado, nuestro enigma central no solo implica procesos de intersubjetividad, sino también dinámicas de la política de poder. De hecho, el alineamiento con la potencia hegemónica es más que una posición identitaria construida bajo interacciones sociales, pues también está determinado por las capacidades materiales. Nuestro enfoque teórico, entonces, se ubica en la intersección del constructivismo y el realismo.

Por lo tanto, consideramos que el constructivismo realista, esbozado desde el trabajo seminal de Barkin (2004; 2010), nos brinda una aproximación enriquecedora. La idea central que recogemos de dicho autor es que uno de los puentes entre el realismo y el constructivismo es el reconocimiento de las contingencias históricas como la base sobre la cual se fundamentan las interacciones sociales (Barkin, 2010, p. 166). Igualmente, damos importancia al cambio histórico como el proceso a través del cual se construyen las ideas y se interpretan las capacidades materiales de los Estados. Esta premisa implica una posición en el debate teórico afín al eclecticismo analítico, el cual cuestiona los enfoques que buscan construir abstracciones ahistóricas, separadas de la política (Katzenstein \& Sil, 2008). Además, nos distanciamos de las miradas estructuralistas que desestiman la capacidad de agencia de los países menos poderosos (Waltz, 1979). 
Aunque Barkin $(2004 ; 2010)$ resalta el papel del historicismo, no detalla los conceptos específicos con los que se podría ensayar una aproximación empírica al alineamiento de política exterior. Debido a esa omisión, consideramos que dos definiciones provistas por el institucionalismo histórico pueden servir a ese propósito, a saber: coyuntura crítica y trayectoria dependiente. Ambos conceptos están interrelacionados. De acuerdo con Pierson y Skocpol (2008), "los resultados en una coyuntura crítica desatan mecanismos de retroalimentación que refuerzan la recurrencia de un patrón particular en el futuro" (p. 13). En otras palabras, cuando suceden coyunturas históricas críticas, los actores políticos toman decisiones que tienen repercusiones de larga duración; estas generan trayectorias dependientes que limitan las alternativas de cambio para los tomadores de decisiones. Ambos conceptos nos son útiles para identificar que los países de la AP decidieron alinearse con EE. UU. durante coyunturas críticas que pueden preceder a la existencia del bloque regional. En adición, sugiere que la alineación se decide bajo situaciones especiales y breves, en las que se abre la posibilidad de redefinir la política exterior.

Los vínculos teóricos entre el realismo y el constructivismo también son posibles tras identificar un traslape en el concepto de poder de ambas teorías. Aunque el realismo tiene un énfasis sobre la incidencia de factores materiales, también demanda una comprensión relacional del poder, el cual es común al constructivismo (Barkin, 2010, p. 169). Como consecuencia, a través de nuestro enfoque, identificamos que el alineamiento es una relación coconstitutiva entre los países latinoamericanos y la potencia hegemónica. Sin duda, esa relación está caracterizada por la asimetría de poder, pero también por la interpretación conjunta de conceptos de seguridad. En otras palabras, entendemos el alineamiento como un producto de interacciones sociales históricamente determinadas, por lo que no es sinónimo de subordinación militar o dominación ideológica.

Desde nuestro punto de vista, es posible observar las relaciones con la potencia hegemónica más allá de la dicotomía autonomía-dependencia, que fue central en el debate académico latinoamericano de la Guerra Fría (Russell \& Tokatlian, 2002). En la actualidad, apreciamos 


\section{8 / Javier Ernesto Ramírez Bullón - Alexandra Pérez Jiménez - Reynell Badillo Sarmiento}

un contexto histórico diferente en el que la difusión del poder internacional y la mayor complejidad de las relaciones centro-periferia hacen más difícil dilucidar las relaciones entre países emergentes y grandes potencias (Hurrell, 2013; Strange, 1996). Dicho escenario nos motivó a cuestionar los paradigmas convencionales que evalúan la política exterior de los países latinoamericanos en función de antagonismos o dicotomías (Russell \& Tokatlian, 2009; 2011).

Si bien nuestro punto de vista nos hace críticos de la manera en que se tienden a estudiar las relaciones entre América Latina y EE. UU., consideramos que existen elementos del debate tradicional que siguen vigentes y merecen ser retomados. Por ejemplo, de acuerdo con Paul Johnson (1986), en una relación entre dominante y subordinado es prematuro sostener que el objetivo principal de la política exterior del país subordinado es lograr una soberanía genuina. Esto se debe a que los países subordinados pueden desear un apalancamiento de esa relación bajo intereses diversos, como obtener protección del hegemón, tener una mejor posición de acceso al comercio y conseguir inversiones o respaldo frente a la subversión de grupos domésticos (Becerra, 2013, p. 88). Así, consideramos que uno de los consensos más importantes que debemos valorar del debate latinoamericano es que las ideas de autonomía o alineamiento no son concepciones definidas como oposición frente a las grandes potencias ni consisten en atributos mutuamente excluyentes (Brands, 2008; van Klaveren, 2014).

Por otro lado, en la literatura de política exterior persisten premisas estructurales que debemos cuestionar desde nuestra mirada teórica. Pese a sus diferencias, tanto las nociones de gran estrategia de Russell y Tokatlian (2013), como el realismo periférico de Schenoni y Escudé (2016) comparten una visión de la política internacional que interpreta la capacidad de agencia de los países únicamente en función de sus capacidades de poder material. Las identidades colectivas o las intersubjetividades son factores omitidos en ambos enfoques. ${ }^{1}$ Es cierto que estos autores incluyen el papel de la ideología o las ideas para crear

\footnotetext{
1 En general, entendemos que la noción de identidad comprende al conjunto de rasgos o elementos propios que distinguen a un ente de otro (normas, ideas, creencias, cultura, etc.).
} 
actitudes de alineamiento con la potencia hegemónica, pero esos términos reciben tratamientos superficiales. ${ }^{2}$ Para Russell y Tokatlian (2013, p. 174), la ideología es equivalente a interés económico de las élites nacionales o a la ideología política de los presidentes, mientras que para Schenoni y Escudé (2016, p. 3), el concepto de idea corresponde a las formulaciones de la academia o a conceptos ambiguos como interés nacional.

A diferencia de las aproximaciones estructuralistas, el realismo constructivista nos sugiere que las ideas tienen una naturaleza más compleja y su capacidad de incidir sobre la política exterior es tan importante como las variables materiales. Por consiguiente, las ideas intersubjetivas son modos de pensar la política que están codificados en la cultura, la cual puede no estar representada en documentos formales. Por otro lado, las ideas y el discurso inciden en la política exterior porque son los elementos a través de los cuales se interpretan las capacidades materiales relativas y las piezas clave que construyen identidades de política exterior que, finalmente, generan pautas de comportamiento (Hopf, 2002; Kubalkova, 2001). De esta reflexión se desprende la necesidad de utilizar múltiples fuentes de información textual y discursiva para examinar empíricamente el rol de las ideas en la política exterior.

\section{Metodología}

A partir de los presupuestos del realismo constructivista, este artículo desarrolla la siguiente estrategia metodológica: 1) se reconstruye el proceso histórico de cooperación en seguridad entre EE. UU. y los países de la AP (a fin de verificar esas alianzas materiales que producen asimetría); 2) se codifican y analizan los discursos de las EPE de los países de la AP en la Asamblea General y el Consejo de Seguridad de

\footnotetext{
2 Utilizamos una definición constructivista del concepto de idea según la cual se trata de modelos mentales compartidos, que tienen un rol constitutivo en la comprensión y el comportamiento (Wendt 1999). Al respecto, tanto la visión sistémica como no sistémica manejan nociones semejantes.
} 
las Naciones Unidas (CSNU) frente a EE. UU. en comparación con los países de Mercosur; ${ }^{3}$ 3) se identifica el grado de similitud o divergencia en el pensamiento de seguridad de los países de la AP al interior de sus libros blancos de defensa, y 4) se evalúa la interrelación entre ideas liberales y nociones de seguridad en la constitución del alineamiento de los países de la AP con EE. UU.

Primero, revisamos los lazos históricos de cooperación bilateral en materia de seguridad con base en fuentes documentales. Por medio de esta aproximación, buscamos identificar las coyunturas críticas en las cuales se definió la alineación con EE. UU. Al realizar este análisis histórico, observamos las tendencias de cooperación en términos de asistencia militar-policial, entrenamiento y compra de armamento. Además, resaltamos las principales decisiones o acuerdos gubernamentales que incrementaron los lazos de cooperación en seguridad entre los países de la AP y EE. UU. ${ }^{4}$

Para observar el grado de alineación de los miembros de la AP con EE. UU., revisamos las votaciones de tales países en el Consejo de Seguridad, así como los discursos presidenciales en la Asamblea General de la ONU. Seleccionamos seis coyunturas clave como periodo de observación: Afganistán 2001, Irak 2003, Libia 2011, Yemen 2012, Siria 2014 e Irán 2014. Tales eventos son relevantes porque fueron coyunturas en las que EE. UU. usó ideas del orden liberal para legitimar una intervención militar. De forma general, las coyunturas críticas de seguridad activan comportamientos de política exterior particulares, pues son momentos en los que se redefinen conceptos compartidos de seguridad y se manifiestan alianzas militares. Por ejemplo, las intervenciones militares de EE. UU. en Medio Oriente buscaban ser legitimadas por

\footnotetext{
3 Es importante resaltar que no se comparan aspectos de la AP y del Mercosur asumiendo que se trata de dos entes que se pueden considerar semejantes; los comparamos con base en su condición de mecanismos regionales de entendimiento. No son de interés para nuestro análisis las políticas comunes de esos bloques, sino las posiciones de sus países y los patrones de política exterior que estos grupos de países han configurado en relación con EE. UU.

4 Centramos la revisión histórica de los cuatro países en el siglo XxI, pero también incluimos algunos antecedentes más antiguos para Chile y Perú, en la medida que nos permitían identificar algunas particularidades de sus relaciones con EE. UU.
} 
narrativas como la lucha contra el terrorismo internacional, la promoción de la democracia y la protección de los derechos humanos (Weiss \& Thakur, 2010, p. 320). Precisamente estos discursos no son ajenos a la experiencia histórica de los países de la AP, ya que tienden a identificarse con valores liberales y posicionarse con severidad en contra del terrorismo. Por ello, dichos momentos históricos son útiles para identificar entendimientos comunes de seguridad entre los países de la AP y explorar si esto configura una alineación colectiva con EE. UU.

Reconstruimos el porcentaje de coincidencia entre cada país con los miembros permanentes del CSNU y en comparación con los demás países latinoamericanos presentes durante el mismo periodo, en especial, los miembros del Mercosur ampliado. También incluimos a la Asamblea General de la ONU dentro del análisis, ya que es un espacio en el que todos los países ejercen su derecho al voto, lo cual permite examinar el alineamiento en perspectiva comparada con otras grandes potencias y países de la región. ${ }^{5}$

Para explorar el rol de las ideas comunes en los Estados aplicamos el método de análisis temático, el cual nos permitió medir la frecuencia y revisar la sustancia de ideas fuerza presentes en el discurso. Al aplicar esta técnica seguimos las recomendaciones que proveen los estudios en comunicación política (Burgué et al., 2010; Riorda, 2008) y las movidas metodológicas centrales de este tipo de análisis: contar, identificar, describir e interpretar (Alhojailan, 2012). Por medio de esta herramienta analizamos los discursos presidenciales que se realizaron en la Asamblea General de la ONU durante los años en que se discutieron las intervenciones militares de EE. UU. De modo complementario, comparamos los libros blancos de seguridad de los países de la AP y del Mercosur. Con esto, desciframos la presencia y correlación entre ideas de seguridad y economía al interior de la AP. De esta manera, nuestro análisis se complementa con los postulados del realismo - las capacidades materiales y los vínculos construidos alrededor de estas explican las decisiones de política exterior de los Estados-y del constructivismo

\footnotetext{
5 En este sentido, seguimos una metodología cuantitativa para medir el alineamiento porque provee una primera aproximación representativa que todavía no existe en la literatura.
} 
— son las ideas que se construyen entre los actores las que explican las decisiones de política exterior-.

\section{Trayectorias históricas de cooperación en materia de seguridad con EE. UU.}

\section{Colombia}

El evento más importante que generó cambios en la cooperación en seguridad entre Colombia y EE. UU. fue el Plan Colombia. Este fue un paquete de ayudas internacionales destinado a la consecución de la paz, pero que con sus posteriores modificaciones terminó focalizado en la lucha contra el narcotráfico y las organizaciones insurgentes (Guevara, 2015). La magnitud de esto fue tal que, entre 1998 y 2016, EE. UU. representó para Colombia cerca del $60 \%$ del total de ayuda oficial al desarrollo recibida (OCDE, 2018). Si se agrega a esto los gastos militares, la cifra llegaría a estar en cerca de los 14182 millones de dólares (USAID, 2018). Este proceso de inclusión de actores internacionales para que contribuyeran a la derrota militar de actores armados al interior del país es conocido como la internacionalización del conflicto armado (Borda, 2007; Tickner, 2007).

Debido a que antes del Plan Colombia hubo momentos en los que actores externos fueron incluidos en el combate a organizaciones insurgentes, algunos autores sugieren que el conflicto armado colombiano se había internacionalizado mucho antes de la presidencia de Andrés Pastrana Arango. ${ }^{6}$ No obstante, aunque pueda ser cierto que el Plan Colombia no fue el primer escenario de cooperación internacional con EE. UU., sí desencadenó una coyuntura crítica, cuyos efectos fueron de largo plazo.

En primer lugar, tal como explica Ramírez (2004), para finales de la década de los noventa, el Estado colombiano estaba en una situación

\footnotetext{
6 Para una revisión sobre la internacionalización del conflicto armado en Colombia, revisar Galeano et al. (2019, pp. 59-62).
} 
de extrema debilidad frente a los actores armados ilegales. Estos últimos habían escalado el conflicto y se habían fortalecido de forma tal que llegaron a actuar en importantes espacios político-económicos del territorio nacional. Además, habían trascendido de su condición de grupos armados esencialmente rurales y pobremente financiados, a poderosos actores capaces de afectar centros de poder en el territorio, en parte ayudados por las rentas provenientes del narcotráfico (Echandía, 2000).

En segundo lugar, el Gobierno de Ernesto Samper (1994-1998) tuvo serios tropiezos en su relación con EE. UU. luego de que se descubriera que a su campaña habían ingresado dineros provenientes del narcotráfico. Esta crisis en las relaciones bilaterales llegó al punto de que se le canceló la visa al expresidente y el país fue descertificado entre 1996 y 1997 (Rojas, 2006). Es decir, en el contexto en el que Pastrana llegó a la presidencia, la "relación especial" entre Colombia y EE. UU. estaba fuertemente cuestionada y, por ende, la política exterior debía repensarse a fin de reinsertarse en las lógicas norteamericanas. ${ }^{7}$

Finalmente, aunque durante sus primeros años de Gobierno Pastrana intentó involucrar al Gobierno norteamericano en el proceso de paz que iniciaba con la otrora guerrilla de las FARC-EP, eventos como el asesinato de tres ciudadanos norteamericanos por parte de este grupo armado y las críticas que este país hacía a la "zona de despeje” que se había establecido - hasta el punto de condicionar la ayuda militar al diseño de un plan para luchar contra el narcotráfico- mantuvieron las tensiones entre estos dos países y dificultaron la cooperación en materia de seguridad (González et al., 2015). En ese sentido, la planeación y ejecución del Plan Colombia no solo respondió a la necesidad de encontrar recursos para esta transformación, sino que era

\footnotetext{
Debe considerarse que, desde principios del siglo xx, Colombia ha mantenido una relación cercana con EE. UU. (Bernal \& Tickner, 2017). Por tanto, en este apartado no estamos afirmando que el Plan Colombia haya sido la coyuntura crítica que definió la cercanía de los países, sino que fue un momento que permitió relanzar la relación bilateral en materia de seguridad luego de la crisis generada durante el Gobierno de Samper.
} 
también una estrategia para reinsertar al país dentro de las lógicas de cooperación con EE. UU. ${ }^{8}$

\section{Chile}

Durante la Guerra Fría, Chile se convirtió en un actor que merecía especial atención en la política exterior norteamericana (Hurtado, 2016). El golpe de Estado que derrocó al gobierno de izquierda de Salvador Allende en 1973 e instauró el dominio de Augusto Pinochet fue uno de los hitos representativos de la confrontación ideológica que vivía el mundo en aquel momento. Algunos autores señalan que EE. UU., a través del Plan Cóndor, tuvo gran responsabilidad en el curso de este tipo de procesos (Paredes, 2004), tan frecuentes en la región latinoamericana, especialmente en el Cono Sur, durante buena parte del siglo Xx. Sin embargo, a pesar de que varias administraciones estadounidenses (como las de Nixon y Ford) respaldaron el gobierno militar de Pinochet, la presidencia de Carter fue menos benevolente y, a mediados de los ochenta, debido a presiones provenientes del Congreso norteamericano, adoptó una postura más crítica respecto a la dictadura chilena (Wilhelmy \& Durán, 2003).

La transición hacia un gobierno democrático, que empezó en la década de los noventa, fue un marco de acercamiento entre los dos países y supuso la restauración de sus relaciones diplomáticas. La primera administración chilena del siglo XXI, en cabeza de Ricardo Lagos (2000-2006), se encuentra registrada en la historia con gran trascendencia, debido a que Chile - por ese entonces miembro del CSNU - no respaldó la disposición de Washington de invadir Irak en retaliación por los acontecimientos del 11 de septiembre de 2001.

\footnotetext{
8 A pesar de que Monroy (2014) ha mostrado consistentemente que el Plan Colombia fue una estrategia de política exterior norteamericana, esto no necesariamente implica que Colombia solo haya participado pasivamente en su adopción. De hecho, Monroy y Sánchez (2017) afirman, luego, que el Plan Colombia fue también el resultado de una estrategia pensada para convencer al gobierno norteamericano de la necesidad de asistir a Colombia y transformar la imagen de Estado fallido en el imaginario norteamericano. En ese sentido, coincidimos en afirmar que no son excluyentes ambas visiones: por supuesto que fue una estrategia de política exterior de los EE. UU., pero también fue una estrategia pensada y ejecutada desde Colombia.
} 
Las relaciones entre EE. UU. y Chile, que se venían normalizando, experimentaron tensiones en esta coyuntura. Las negociaciones comerciales que ambos países adelantaban en aquel tiempo, gracias al mutuo interés por parte de Bush y Lagos, tambalearon.

Por un lado, Lagos se encontró frente a la encrucijada de cumplir con dos de los objetivos de su política exterior: suscribir un tratado de libre comercio con la primera potencia mundial y demostrar coherencia con la intención chilena de reinsertarse en el escenario internacional enarbolando las banderas de la democracia liberal (Bywaters, 2014). Por otro lado, a Bush le resultaba favorable firmar el acuerdo comercial con el país suramericano para avanzar su interés de estrechar lazos con la región; al mismo tiempo, esperaba que un potencial socio como Chile respaldara con su voto a favor de la intervención en Medio Oriente (Agüero, 2005). Finalmente, el gobierno chileno le dio prevalencia a una política de prestigio y no secundó las operaciones militares estadounidenses en Irak. Sin embargo, esto no impidió que, con posterioridad, el tratado de libre comercio entre Chile y EE. UU. se suscribiese. Chile venció en los dos frentes y a partir de este impasse sus relaciones con los estadounidenses resultaron más robustas.

En adelante, los gobiernos de Michelle Bachelet y Sebastián Piñera se esmeraron por conservar y profundizar las relaciones con la potencia del norte (Valdivieso, 2015). En la última década, EE. UU. reconoció que apoya el liderazgo de Chile en la región en relación con la promoción de "los beneficios de la democracia y el libre mercado" (Embajada de los Estados Unidos en Chile, 2019). De acuerdo con el Servicio de Investigación del Congreso de EE. UU., debido al nivel de desarrollo de Chile, la ayuda económica exterior que este país recibe por parte del gobierno estadounidense se ha concentrado sobre todo en asistencia orientada a asuntos de seguridad. Entre 2011 y 2013, por ejemplo, Chile recibió más de 3 millones de dólares para este fin (Meyer, 2014).

Adicionalmente, Chile ha recibido flujos de cooperación y asistencia técnica, en especial, en el ámbito militar. Los esfuerzos han estado encaminados a mejorar la interoperabilidad entre las fuerzas chilenas y 
las fuerzas norteamericanas; al mismo tiempo, se ha buscado reforzar la capacidad de este país para participar en operaciones de mantenimiento de la paz. Chile permitió, por ejemplo, la instalación del Fuerte Aguayo, construido con el propósito de albergar actividades del Centro Conjunto para Operaciones de Paz (CECOPAC), el cual incluye ejercicios de entrenamiento militar con soldados estadounidenses (Luzzani, 2012). A mediados de 2018, estos dos países firmaron una declaración conjunta con el propósito de cooperar en el área de ciberdefensa a través de intercambios, ejercicios conjuntos y capacitación. Al respecto, el presidente chileno recalcó: "sin duda que queremos que esta relación privilegiada con Estados Unidos no solamente se mantenga, queremos fortalecerla, proyectarla a nuevos desafíos, a nuevas misiones" (Ministerio de Defensa Nacional de Chile, 2018).

A diferencia de los otros países de la AP, la cooperación en seguridad entre Chile y EE. UU. no obedeció a condiciones contextuales nacionales que requerían de apoyo exterior, sino más bien a fortalecer una de las dimensiones que se creían parte del "modelo exitoso" chileno. Dicho de otro modo, en los casos de Colombia, México y Perú, las iniciativas de cooperación con EE. UU. respondían a esfuerzos conjuntos por combatir la insurgencia, el crimen organizado y el terrorismo al interior de esos territorios. Mientras tanto, en las circunstancias de Chile, la cooperación estadounidense en este sector se ha orientado a desarrollar y fortalecer las capacidades de las fuerzas chilenas para operar como un actor regional y global, por ejemplo, en escenarios de programas de mantenimiento de la paz.

\section{México}

En el caso mexicano también puede observarse que hay una larga relación de cooperación militar entre ambos países. Como menciona Chacón (2000), la cercanía geográfica y la amplia frontera compartida no podían pasar desapercibidas para EE. UU. No obstante, ha sido desde comienzos de la primera década del segundo milenio cuando esta relación de cooperación en materia de seguridad adquirió mayor raigambre. Mientras en el 2000, por ejemplo, la ayuda militar y policial proveniente de los EE. UU. alcanzaba los 4,9 millones de dólares, 
en el 2016 la cifra llegó a los 90,6 millones y hubo momentos, en esos tres lustros, en los que alcanzó los 707,9 millones (Benítez \& Aguayo, 2016).

Esta profundización estuvo marcada por los atentados del 11 de septiembre de 2001 y se formalizó a través de acuerdos como la Asociación para la Seguridad y la Prosperidad (ASPAN). Aun así, no puede desconocerse que desde el 2008 una buena parte de esos esfuerzos - inicialmente destinados al resguardo de las fronteras a fin de prevenir acciones terroristas en territorio estadounidense- fueron redirigidos hacia la lucha contra el crimen organizado a través de la Iniciativa Mérida, destinada al fortalecimiento de las instituciones de defensa y seguridad pública (Barreda, 2014).

El gobierno de George W. Bush se comprometió a entregar cerca de 1400 millones de dólares para esta estrategia aunado a la transferencia de tecnología, helicópteros y equipo militar. Con estos fondos, se entrenaron cerca de 8500 funcionarios federales, 19000 policías y se reforzaron 14 centros penitenciarios alrededor del país (Barreda, 2014). Al igual que en el caso colombiano, la existencia de actores armados con actividades transnacionales relacionadas con el narcotráfico en medio de un contexto internacional en el que EE. UU. favorecía su combate resultó ser un catalizador de fuertes vínculos de cooperación en materia de seguridad.

Este esquema de cooperación en el combate contra el crimen transnacional, aunque tiene raíces en la década de los ochenta, se ha fortalecido y ha adquirido una institucionalidad mucho más fuerte desde comienzos del segundo milenio. Particularmente, se pueden observar dos puntos de quiebre en la cooperación militar entre México y EE. UU. La primera coyuntura fueron los atentados del 9/11 que pusieron al terrorismo como principal tema de la agenda y llevaron a Washington a solidificar la seguridad en sus fronteras. Prueba de ello sería la Segunda Directiva Presidencial de Seguridad Nacional en la que Bush ordenó iniciar negociaciones con Canadá y México con el objetivo de garantizar la seguridad fronteriza (Gabriel et al., 2006). Como corolario de este cambio en la visión geopolítica norteamericana aparecen 
el Acuerdo de Fronteras Inteligentes, firmado en marzo del 2002, y la Operación Centinela, en la que participaron cerca de 18000 integrantes de las fuerzas armadas (Benítez \& Rodríguez, 2006).

La segunda, que transformó y, ahora sí, permitió que México ingresara dentro de las dinámicas de cooperación militar estadounidenses fue el requerimiento que hizo el expresidente Felipe Calderón al Gobierno de EE. UU. para que ayudara a combatir el crimen organizado. De esta forma, se dio origen a la Iniciativa Mérida, que significó una nueva etapa en la cooperación bilateral, dado que no solo se transfirieron tecnología y equipos para combatir el crimen transnacional organizado, sino que se inició un proceso de transformación institucional acompañado por EE. UU. México superó así la desconfianza que anteriormente se había gestado en las altas esferas del Gobierno sobre la posibilidad de que esa cooperación implicara demasiado involucramiento de EE. UU. en la política doméstica. A pesar de que este costo, ciertamente, pudo haber sido pagado debido a la reconfiguración institucional que el país está viviendo, los beneficios en términos monetarios son considerables: hasta el 2018 EE. UU. había invertido 2876.8 millones de dólares. En ese sentido, a diferencia de Colombia, la cooperación en materia de seguridad entre EE. UU. y México respondió más a la lucha contra el crimen organizado y la securitización fronteriza que al desarrollo de un conflicto armado.

\section{Perú}

Durante el gobierno militar de Juan Velasco Alvarado (1968-1975), Perú ensayó un ímpetu autonomista en su política exterior que lo distanció de EE. UU. y tuvo repercusiones de larga duración (Alcalde Cardoza \& Romero Sommer, 2014). En el contexto de la Guerra Fría, Perú intentó comprar armamento estadounidense para aplicar un balance de poder frente al gobierno de Pinochet. Sin embargo, debido al respaldo de Nixon sobre el régimen militar chileno, Perú no obtuvo el respaldo que buscaba en términos de seguridad y viró su atención hacia la entonces Unión Soviética (Brands, 2010, p. 484). Por lo tanto, con el fin de diversificar sus fuentes de armamento, durante ese gobierno, Perú implementó tecnología soviética en sus principales 
sistemas de defensa (Alburquerque, 2017). Esa decisión generó una trayectoria dependiente que continúa hasta hoy. Al tener una matriz de defensa con diversas fuentes que no son occidentales, el Estado peruano tiene más independencia para modernizar su armamento sin la ayuda estadounidense.

Aunque Perú continuó su tradición de diversificar sus proveedores de seguridad, ${ }^{9}$ en la actualidad tiene una relación de cooperación muy cercana con EE. UU. El alineamiento de Perú con la política de seguridad y defensa de los Estados Unidos puede rastrearse a partir de la visita de George W. Bush al Perú a inicios del 2002. Precisamente en ese año, EE. UU. benefició unilateralmente a Perú con la Ley de Preferencias Arancelarias Andinas y Erradicación de la Droga (ATPDEA, por sus siglas en inglés). Dicha iniciativa estimuló a Perú a militarizar el combate contra el tráfico de drogas ilícitas a través del otorgamiento de beneficios comerciales (Olano Alor, 2013). A partir del gobierno de Toledo la cercanía con EE. UU. se intensificó en términos económicos y de seguridad. La firma de un acuerdo de libre comercio con la potencia hegemónica en 2006 fue interpretada por el gobierno peruano como un logro de una política exterior pragmática. Sin embargo, detrás del alineamiento supuestamente desideologizado, la negociación del acuerdo fomentó que Perú interiorizara una identidad liberal de su política exterior afín a la hegemonía estadounidense (Ramírez Bullón, 2018).

Por lo tanto, conforme aumentaron las relaciones comerciales con EE. UU., Perú también mejoró su alineamiento integral con la potencia hegemónica. En el plano de la seguridad internacional, EE. UU. se ha convertido en el socio más importante en cuatro aspectos principales: "la asistencia militar, el entrenamiento, los ejercicios militares conjuntos y la política antidrogas llevada a cabo por el Estado peruano" (Adins Vanbiervliet, 2019, p. 177). En este proceso, Perú recibió más de 1500 millones de dólares de EE. UU., con lo cual se convirtió en el tercer receptor de la región, luego de Colombia (10 mil millones)

\footnotetext{
9 Por ejemplo, ha establecido alianzas de cooperación en materia de seguridad con países como China y Corea del Sur (Infodefensa.com, 2016).
} 


\section{0 / Javier Ernesto Ramírez Bullón - Alexandra Pérez Jiménez - Reynell Badillo Sarmiento}

y México (3265 millones). Además, Perú ha permitido que EE. UU. utilice aeropuertos locales para el aterrizaje y abastecimiento de aviones que sostienen la lucha antidrogas en la región andina (Bitar, 2016, p. 7). De modo similar, el Comando Sur de EE. UU. (SouthCom) opera cerca de 17 puestos de radar entre Perú y Colombia bajo la misma justificación de lucha contra el narcotráfico (Lindsay-Poland, 2009, p. 72).

Entre Perú y EE. UU. solo existen dos acuerdos de cooperación en seguridad, uno de 1952 y el Memorándum de entendimiento para el fortalecimiento de las relaciones político-militares de 2012. A diferencia de México y Colombia, la alineación en seguridad no se constata de manera tan evidente en un acuerdo formal, sino que fue producto de un proceso menos disruptivo. El gobierno de Toledo (2001-2006) representa el momento en que se gestó la subordinación de las políticas antidrogas a los esquemas proyectados por EE. UU., lo cual coincidió con la institucionalización del libre comercio y el regionalismo abierto como ideas directrices de la política exterior peruana. Por ello, consideramos que la coyuntura crítica en que se dio el alineamiento de seguridad coincide con la apertura comercial entre Perú y EE. UU., concretada en 2006.

\section{Tendencias de asistencia militar y policial}

En la figura 1 mostramos datos sobre la asistencia militar ${ }^{10}$ estadounidense que refuerzan lo dicho sobre las trayectorias históricas de los países analizados. Colombia experimentó un crecimiento significativo de la asistencia desde el 2001, justo un año después de que se estableciera el Plan Colombia. De hecho, los montos de esa asistencia entre 2000 y 2017 son 2,4 veces mayores que los que se habían presentado entre 1950 y 2000. Por su parte, en Chile se observa un aumento escarpado

\footnotetext{
10 Por asistencia militar en este texto se está comprendiendo la suma de contratos de venta militares, contratos de venta de construcciones militares, programas de financiamiento militar, programas de asistencia militar y programas de educación y entrenamiento militar internacional. Por tanto, se entiende como asistencia militar la participación de un país dentro de la formación y dotación del ejército de otro Estado aun cuando esto no se haga en forma de donación.
} 
entre 2001 y 2003, luego de esa fecha empezó a crecer el nivel de asistencia militar de forma significativa con respecto a la anterior década. Si se comparan los datos entre los periodos 1950-2000 y 2000-2017 puede observarse que se han triplicado los montos en apenas 17 años.

En México, el aumento de la asistencia militar estadounidense se hizo significativo en el 2008, lo que coincide con la firma de la primera carta de acuerdo sobre la Iniciativa Mérida. En apenas una década (2008-2017), los montos se cuadruplicaron con respecto a los sesenta años anteriores (1950-2008). Perú, como ya fue dicho, recibe menos asistencia militar estadounidense debido a su diversificación de fuentes de defensa. Aun así, desde el 2008 puede observarse un aumento significativo, justo un año después de que el Senado estadounidense ratificara el acuerdo comercial entre los dos países y un año antes de que empezara su implementación. Entre 2008 y 2017, los montos de la asistencia militar llegaron a ser 7,4 veces mayores que los presentados en los 17 años previos.

Figura 1. Asistencia militar estadounidense para países de la AP entre 1995-2017 (miles de dólares)

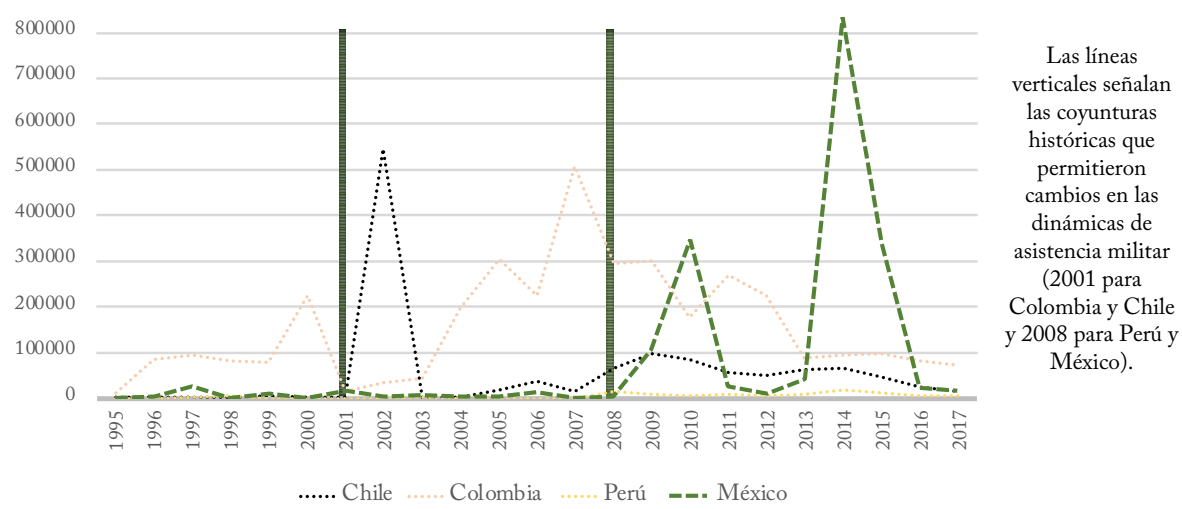

Fuente: elaborado a partir de los informes anuales de la Agencia de Cooperación para la Seguridad y Defensa del Departamento de Estado de EE. UU. almacenados en la base de datos del SIPRI.

Notas: las líneas verticales señalan las coyunturas históricas que permitieron cambios en las dinámicas de asistencia militar (2001 para Colombia y Chile y 2008 para Perú y México).

En la figura 2 encontramos que los países de la AP son los que más estudiantes militares entrenados por EE. UU. tienen con respecto a 
Sudamérica. De hecho, con la excepción de México, todos superan en número a los países del Mercosur ampliado. Frente al reducido número de México, es necesario mencionar que cerca de la mitad de esos estudiantes fueron formados entre el 2000 y el 2017, lo que reafirma nuestro planteamiento sobre la existencia de dos momentos de quiebre en México: uno al comenzar el nuevo milenio (2000) y el siguiente con la Iniciativa Mérida. Esa excepción demuestra, por un lado, el recelo que había en México con respecto a permitir que EE. UU. se inmiscuyera en sus asuntos internos y, por otro, la forma en que esa prevención se ha venido disipando progresivamente en asuntos de seguridad y defensa desde el 2000 — ya sea que se evidencie a través de montos de asistencia militar o de militares formados por EE. UU.—.

Figura 2. Estudiantes entrenados por EE. UU. durante programas de educación y entrenamiento militar (1950-2017)

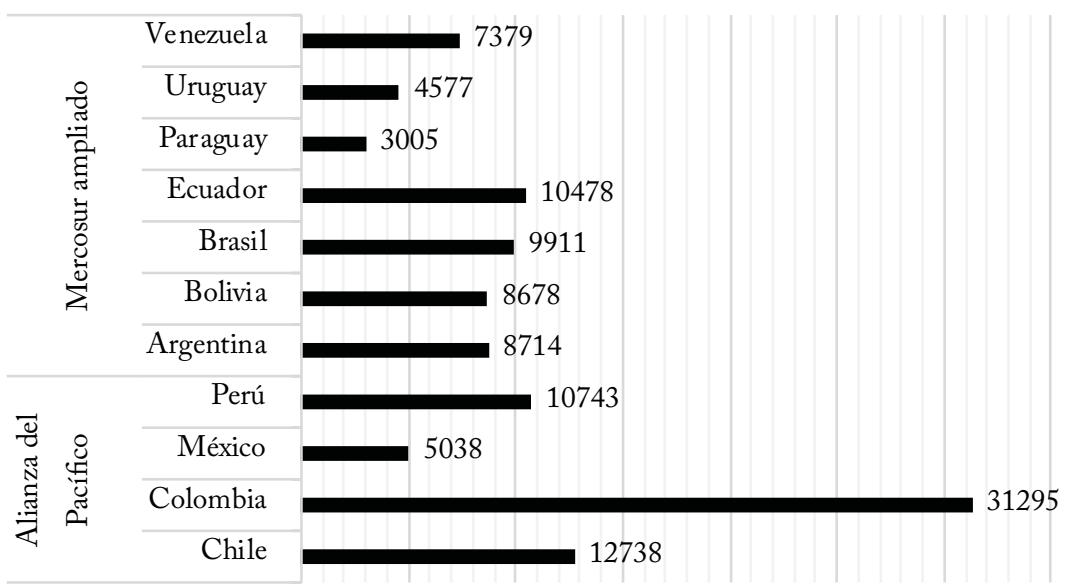

Fuente: elaborado a partir de los informes anuales de la Agencia de Cooperación para la Seguridad y Defensa del Departamento de Estado de EE. UU. almacenados en la base de datos del SIPRI.

La figura 3 evidencia el argumento que hemos sostenido sobre la estrecha relación de seguridad que tienen los países de la AP con EE. UU. El monto de asistencia militar estadounidense que recibe la AP duplica al del Mercosur ampliado pese a que este tiene siete países y la AP, cuatro. Aun sin Colombia, que es el mayor receptor de asistencia militar en la región, México, Chile y Perú superan a los siete países 
del Mercosur. Por ello se sostiene que la AP se alinea con EE. UU. en asuntos de seguridad y defensa de forma más consistente que otros bloques regionales. ${ }^{11}$

\section{Figura 3. Asistencia militar estadounidense para los países de la AP y Mercosur ampliado (1995-2017)}

\section{Alianza del Pacífico Mercosur ampliado}

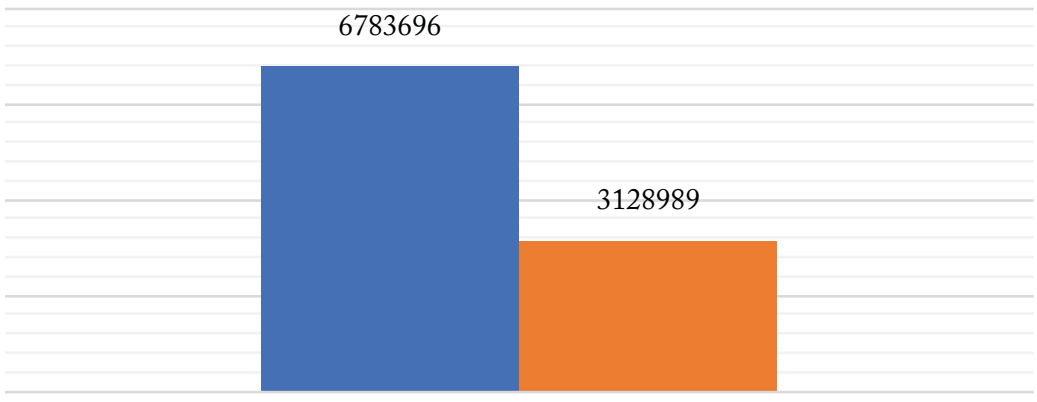

Asistencia militar estadounidense entre 1995-2017 (miles de dólares)

Fuente: elaborado a partir de los informes anuales de la Agencia de Cooperación para la Seguridad y Defensa del Departamento de Estado de EE. UU. almacenados en la base de datos del SIPRI.

Si consideramos los datos de ayuda policial y militar (en los que ya no se incluyen las compraventas ni los programas de asistencia que sean pagados por los países receptores), la alineación de los países de la AP frente a EE. UU. se hace mucho más evidente. Colombia y México son los mayores receptores entre los países de la región. Sin embargo, solo lo que recibe Perú en este rubro es equivalente a lo que reciben los siete países del Mercosur ampliado juntos. De hecho, los países de la AP juntos reciben 10 veces lo que los países del Mercosur ampliado (tabla 1).

Chile, por su parte, se separa de esta tendencia por dos razones. En primer lugar, la cooperación en este país se ha dado principalmente

\footnotetext{
11 En este artículo, entendemos la noción de bloque regional como un espacio en el que las relaciones entre países vecinos se profundizan con más vehemencia en uno o varios ámbitos en comparación con las relaciones con el resto del mundo. No hacemos referencia a un proceso de integración en sentido ortodoxo, sino más bien a un modelo de región laxo.
} 


\section{I Javier Ernesto Ramírez Bullón - Alexandra Pérez Jiménez - Reynell Badillo SARMiento}

en términos de compra y venta de armamento y entrenamiento militar. Es decir, si bien EE. UU. es uno de los principales aliados en términos de seguridad y defensa para Chile, esta alianza se gesta no en términos de ayudas, sino de cooperación militar que usualmente Chile costea. En segundo lugar, los datos sobre ayuda policial y militar se ven afectados por los programas de asistencia para combatir el narcotráfico — lo que explica que sea superado por Bolivia, Ecuador y Brasil, que justamente reciben la mayor parte de sus ingresos del programa de Control Internacional de Narcóticos y Aplicación de la Ley-. En ese sentido, ya sea a través de asistencia militar o de ayuda policial y militar, los países de la AP encuentran en EE. UU. un aliado esencial en materia de seguridad y defensa y, además, se relacionan con este país de forma mucho más profunda que los países de otro bloque regional, como el Mercosur.

Tabla 1. Ayuda policial ${ }^{12}$ y militar recibida por los países de la AP y Mercosur ampliado entre 2000-2020 (en dólares)

\begin{tabular}{|l|l|}
\hline \multicolumn{1}{|c|}{ País } & \multicolumn{1}{c|}{ Monto recibido } \\
\hline Colombia & $\$ 10324285182$ \\
\hline México & $\$ 3332676584$ \\
\hline Perú & $\$ 1575912979$ \\
\hline Bolivia & $\$ 884917744$ \\
\hline Ecuador & $\$ 480370949$ \\
\hline Brasil & $\$ 94417367$ \\
\hline Venezuela & $\$ 57464454$ \\
\hline Argentina & $\$ 53865831$ \\
\hline Chile & $\$ 51198924$ \\
\hline Paraguay & $\$ 39750203$ \\
\hline Uruguay & $\$ 17317437$ \\
\hline
\end{tabular}

Fuente: elaborado a partir de la base de datos de Security Assistance Monitor.

\footnotetext{
12 En esta tabla se incluyen también los datos de ayuda policial, por lo que puede haber variaciones con respecto a las anteriores figuras. La razón es que, si bien en Colombia y México la lucha contra el narcotráfico y el crimen organizado ha llevado a una militarización de estos fenómenos, en Perú la lucha contra el crimen organizado ha estado asociada más a labores policiales, por lo que se observan variaciones en ambos indicadores.
} 


\section{La interrelación entre ideas liberales y conceptos de seguridad}

Este apartado presenta el análisis temático de los discursos presidenciales y de los libros blancos de defensa de los miembros de la AP, del Mercosur y de EE. UU. Mediante este método rastreamos las nociones compartidas que motivan el alineamiento de la AP con la potencia norteamericana. Hacia el final, mostramos el grado de coincidencia entre las votaciones de los países de la AP y EE. UU. en los principales foros políticos internacionales.

\section{Las ideas liberales de la $A P$}

Para medir la presencia de las ideas fundacionales de la AP en cada Estado relacionamos los conceptos de liberalismo económico y democracia liberal. Además, incluimos la medición del concepto de soberanía nacional como proxy de la noción de autonomía en la política exterior. Medimos cada idea a través del conteo de palabras clave teniendo en cuenta el significado y la sintaxis de los textos analizados. En la tabla 2 mostramos las frecuencias e indicamos los nodos semánticos para cada concepto.

Tabla 2. Frecuencia de las ideas liberales de la AP en discursos presidenciales pronunciados ante la Asamblea General de la ONU

\begin{tabular}{|c|c|c|c|c|c|}
\hline & 2001 & 2003 & 2011 & 2012 & 2014 \\
\hline \multicolumn{6}{|c|}{ Liberalismo económico* } \\
\hline Colombia & 1 & 11 & 6 & 10 & 10 \\
\hline Chile & 12 & - & 33 & 33 & 33 \\
\hline México & - & - & 7 & 26 & 19 \\
\hline Perú & - & - & 30 & 12 & 41 \\
\hline \multicolumn{6}{|c|}{ Democracia liberal** } \\
\hline Colombia & 4 & 19 & 6 & 5 & 3 \\
\hline Chile & 12 & - & 9 & 18 & 15 \\
\hline México & - & - & 2 & 8 & 18 \\
\hline Perú & - & - & 9 & 15 & 7 \\
\hline \multicolumn{6}{|c|}{ Soberania nacional*** } \\
\hline Colombia & 0 & 1 & 0 & 1 & 0 \\
\hline Chile & 0 & - & 3 & 5 & 1 \\
\hline
\end{tabular}




\section{6 / Javier Ernesto Ramírez Bullón - Alexandra Pérez Jiménez - Reynell Badillo Sarmiento}

\begin{tabular}{|l|l|l|l|l|l|}
\hline & $\mathbf{2 0 0 1}$ & $\mathbf{2 0 0 3}$ & \multicolumn{1}{|c|}{$\mathbf{2 0 1 1}$} & $\mathbf{2 0 1 2}$ & $\mathbf{2 0 1 4}$ \\
\hline México & - & - & 0 & 0 & 4 \\
\hline Perú & - & - & 3 & 2 & 1 \\
\hline
\end{tabular}

Fuente: elaborado con base en archivos de los ministerios de relaciones exteriores de Colombia, Chile, México, Perú y los archivos de la Asamblea General de la ONU.

Notas:

*Nodos: libre comercio, desarrollo, cooperación, regionalismo.

**Nodos: gobernabilidad, democracia, derechos humanos, gobernanza global.

***Nodos: independencia, autonomía, soberanos, integridad, no intervención.

A partir de las intervenciones presidenciales confirmamos que los países de la AP comparten un discurso a favor de la democracia y el libre mercado. Además, las menciones a tales conceptos superan las referencias al principio de autonomía de política exterior. Es importante destacar que no todos los países de la AP defienden las ideas liberales con el mismo ímpetu. Chile y Perú tienden a enfatizar con más vehemencia las nociones de democracia y libre mercado en contraposición a Colombia y México. Igualmente, cuando se alude a la soberanía nacional, Chile y Perú son más reiterativos al referirse al principio de no intervención. A pesar de estos matices, encontramos los primeros rasgos de una identidad colectiva en la AP, que precede a su propia fundación. Si bien vemos una convergencia en ideas económicas, también encontramos una desatención sobre el ideal de autonomía.

\section{Ideas de seguridad en los libros blancos de defensa}

Podemos evaluar la presencia de ideas de seguridad en los países de la AP a partir del reconocimiento común que hacen sus Estados miembro frente a amenazas internacionales en sus libros blancos de defensa. Como punto de comparación incluimos a los países del Mercosur y a EE. UU. En la tabla 3 detallamos los enunciados principales de cada ítem a partir del análisis textual. 
Tabla 3. Identificación de amenazas por parte de los países de la AP, del Mercosur y EE. UU.

\begin{tabular}{|c|c|}
\hline & Caracterización de amenazas \\
\hline Chile & $\begin{array}{l}\text { Defensa de la soberanía nacional, terrorismo, delincuencia organizada } \\
\text { transnacional, drogas, corrupción, lavado de activos, tráfico de armas, } \\
\text { pobreza extrema, exclusión social, desastres naturales, VIH/SIDA, trata } \\
\text { de personas, seguridad cibernética. }\end{array}$ \\
\hline Colombia & $\begin{array}{l}\text { Terrorismo, negocio de las drogas ilícitas, finanzas ilícitas, tráfico de } \\
\text { armas, municiones y explosivos, secuestro y extorsión, homicidios. }\end{array}$ \\
\hline México & $\begin{array}{l}\text { Vigilancia de soberanía nacional, combate al tráfico ilícito de drogas, } \\
\text { restauración del ecosistema y preservación de recursos naturales, } \\
\text { salvaguardar vida y bienes de la población ante desastres naturales y } \\
\text { producidos por el hombre. }\end{array}$ \\
\hline Perú & $\begin{array}{l}\text { Defensa de la soberanía nacional, garantizar plena vigencia de los } \\
\text { derechos humanos, proteger a la población de las amenazas contra su } \\
\text { seguridad y promoción del bienestar general. }\end{array}$ \\
\hline Argentina & $\begin{array}{l}\text { Terrorismo internacional, deterioro del medio ambiente, desigualdad en } \\
\text { la distribución de la riqueza, trata de personas, piratería, narcotráfico. }\end{array}$ \\
\hline Bolivia & $\begin{array}{l}\text { Agresión externa, pobreza, exclusión social, racismo, corrupción, } \\
\text { narcotráfico, depredación del medio ambiente, terrorismo, crimen } \\
\text { organizado, tráfico de armas. }\end{array}$ \\
\hline Brasil & $\begin{array}{l}\text { Ataques externos, preservación de la soberanía y la integridad } \\
\text { territorial, garantía de los derechos y deberes constitucionales, } \\
\text { terrorismo internacional, amenazas a la Amazonía. }\end{array}$ \\
\hline EE. UU. & $\begin{array}{l}\text { Agresión territorial y contra el pueblo, armas de destrucción masiva, } \\
\text { extremismo violento, preservación de conectividad global (comercio } \\
\text { marítimo), ciberseguridad, Estados fallidos, terrorismo, redes } \\
\text { criminales, piratería. }\end{array}$ \\
\hline
\end{tabular}

Fuente: elaborado con base en los libros blancos de defensa de cada país publicados en la Comisión de Seguridad Hemisférica de la Organización de Estados Americanos (OEA).

Encontramos que todos los países han interiorizado al menos algunos aspectos de amenazas no convencionales dentro de sus doctrinas de seguridad. Una idea que parece diferenciar a los países de la AP de los del Mercosur es la prioridad del terrorismo. Si bien en todos los países esta es una amenaza latente, en los países de la AP existe un mayor tratamiento sobre los dispositivos que los Estados han desarrollado para mitigarlo. Además, los países del Mercosur se refieren al terrorismo internacional con mayor énfasis que al terrorismo interno. Esto sucede a la inversa en el caso de los países de la AP. También es llamativo que los países de la AP enuncian más sus amenazas en 


\section{8 / Javier Ernesto Ramírez Bullón - Alexandra Pérez Jiménez - Reynell Badillo SaRmiento}

términos de una doctrina de defensa nacional y menos como una evaluación de amenazas externas.

A partir del análisis temático del pensamiento de seguridad que tienen los países de la AP y el Mercosur, respectivamente, se encuentran nuevos elementos que podrían sumarse a lo que hemos definido como la identidad colectiva de la AP. Los países de la AP, en contraposición a los del Mercosur, tienen mayores coincidencias con EE. UU. en la determinación de las amenazas, como por ejemplo el terrorismo.

\section{El grado de alineamiento con EE. UU. en foros internacionales}

Esta sección muestra el alineamiento de política exterior mediante el recuento de votos en los principales foros de deliberación y decisión internacionales. ${ }^{13}$ Para agregar un enfoque comparado, incluimos las posiciones del Mercosur y las grandes potencias que tienen un puesto permanente en el CSNU (tabla 4).

Tabla 4. Porcentaje de coincidencia de votos con EE. UU. en el CSNU por año

\begin{tabular}{|c|c|c|c|c|c|c|c|c|c|c|c|c|c|c|}
\hline & & 2001 & 2002 & 2003 & 2004 & 2006 & 2007 & 2009 & 2010 & 2011 & 2012 & 2014 & 2015 & 2018 \\
\hline \multirow{4}{*}{ 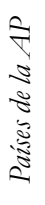 } & Colombia & 96,2 & 97,1 & - & - & - & - & - & - & 100 & 100 & - & - & - \\
\hline & Chile & - & - & 97,1 & 96,7 & - & - & - & - & - & - & 98,4 & 100 & - \\
\hline & México & - & 97,1 & 97,1 & - & - & - & - & - & - & - & - & - & - \\
\hline & Perú & - & - & - & - & 98,9 & 100 & 100 & 100 & - & - & - & - & 96,7 \\
\hline \multirow{7}{*}{ 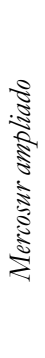 } & Argentina & - & - & - & - & 97,8 & - & , & - & - & - & 98,4 & - & - \\
\hline & Bolivia & - & - & - & - & - & - & - & - & - & - & - & - & 87,5 \\
\hline & Brasil & - & - & - & 96,7 & - & - & - & 98,3 & 96,9 & - & - & - & - \\
\hline & Ecuador & - & - & - & - & - & - & - & - & - & - & - & - & - \\
\hline & Paraguay & - & - & - & - & - & - & - & - & - & - & - & - & - \\
\hline & Uruguay & - & - & - & - & - & - & - & - & - & - & - & - & - \\
\hline & Venezuela & - & - & - & - & - & - & - & - & - & - & - & 74,2 & - \\
\hline
\end{tabular}

13 Queremos señalar que no respaldamos la división que hace el realismo clásico entre política exterior y política internacional. Nuestra aproximación desde el realismo constructivista se decanta por una comprensión coconstitutiva de estas dos dimensiones. 
El alineamiento en seguridad internacional de los países de la Alianza del Pacífico CON ESTADOS UNIDOS: UNA APROXIMACIÓN DESDE EL REALISMO CONSTRUCTIVISTA / 29

\begin{tabular}{|c|c|c|c|c|c|c|c|c|c|c|c|c|c|c|}
\hline & & 001 & 002 & 2003 & 2004 & 2006 & 2007 & 2009 & 2010 & 2011 & 2012 & 2014 & 2015 & 2018 \\
\hline \multirow{4}{*}{ 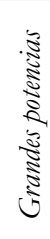 } & & & & & & & & & & & & 4 & ,9 & 36,7 \\
\hline & Rus & 96,2 & 97,1 & 9 & & & 98,1 & 5,9 & 100 & 91,1 & 2 & 78,7 & 69,6 & 82,5 \\
\hline & Francia & 8,1 & 7,1 & 9 & 6,7 & 97,8 & 100 & 100 & 100 & 100 & 100 & 98,4 & 100 & 97,5 \\
\hline & $\begin{array}{l}\text { Reino } \\
\text { Unido }\end{array}$ & 100 & 97,1 & 100 & 100 & 100 & 100 & 100 & 100 & 100 & 100 & 96,9 & 100 & 98,3 \\
\hline
\end{tabular}

Fuente: elaborado con base en datos de securitycouncilreport.org

Cuando los países de la AP han ocupado un puesto en el CSNU suelen coincidir en un $100 \%$ con EE. UU. en sus votaciones. El porcentaje de coincidencia más bajo entre un miembro de la AP y la potencia del norte es de $96 \%$. En contraste, algunos integrantes del Mercosur registran porcentajes de hasta $70 \%$ y $80 \%$, los cuales se acercan a las cifras de potencias desafiantes de EE. UU., como Rusia y China.

Tabla 5. Porcentaje de coincidencia de votos con EE. UU. en la Asamblea General de la ONU

\begin{tabular}{|l|l|c|c|c|c|c|}
\hline & & $\mathbf{2 0 0 1}$ & $\mathbf{2 0 0 3}$ & $\mathbf{2 0 1 1}$ & $\mathbf{2 0 1 2}$ & $\mathbf{2 0 1 4}$ \\
\hline \multirow{4}{*}{ Paises de la } & Colombia & 25,4 & 20 & 51,9 & 40,8 & 40 \\
\cline { 2 - 7 } & Chile & 32,8 & 24,1 & 50 & 39 & 40,7 \\
\cline { 2 - 7 } & México & 22,7 & 20,7 & 50 & 39,7 & 41 \\
\cline { 2 - 7 } & Perú & 27,9 & 23 & 50 & 40,5 & 41,5 \\
\hline \multirow{4}{*}{ Mercosur ampliado } & Argentina & 32,8 & 24,3 & 48,7 & 37,8 & 40,5 \\
\cline { 2 - 8 } & Bolivia & 25,4 & 22,2 & 34,2 & 24,3 & 32,5 \\
\cline { 2 - 7 } & Brasil & 29 & 20,8 & 41,3 & 35,1 & 37,3 \\
\cline { 2 - 7 } & Ecuador & 25,4 & 20,7 & 29,3 & 25,4 & 30 \\
\cline { 2 - 7 } & Paraguay & 33,3 & 23,1 & 44,7 & 34,8 & 48,6 \\
\cline { 2 - 7 } & Uruguay & 29 & 22,5 & 46,8 & 38,7 & 38,6 \\
\cline { 2 - 7 } & Venezuela & 20,9 & 18,5 & 31,7 & 26,4 & 28,2 \\
\hline \multirow{5}{*}{ Grandes potencias } & China & 17,2 & 13,2 & 39,7 & 39,3 & 35,9 \\
\cline { 2 - 7 } & Rusia & 34,5 & 26,4 & 47,2 & 42,9 & 43,9 \\
\cline { 2 - 7 } & Francia & 59,6 & 50,7 & 77,5 & 71 & 76,1 \\
\cline { 2 - 7 } & Reino Unido & 63,2 & 57,1 & 79,7 & 73,8 & 78,9 \\
\hline
\end{tabular}

Fuente: elaborado con base en los informes anuales del Departamento de Estado de EE. UU. sobre las prácticas de votación en la ONU.

Notas: se omitieron en esta tabla las resoluciones adoptadas por consenso, dado que consideramos que estas pueden aumentar artificialmente el porcentaje de coincidencias. 
El alineamiento de los países de la AP con EE. UU. es marcadamente más notorio en el CSNU que en la Asamblea General. En esta, el porcentaje de coincidencia de la AP disminuye a un rango que puede ir desde un $20 \%$ a un $50 \%$. Sin tener en cuenta las resoluciones adoptadas por consenso, los miembros de la AP se comportan de forma parecida a los países del Mercosur e incluso votan como algunas de las grandes potencias contestatarias del orden liberal. Esto pone de relieve que cuando se toman decisiones no vinculantes, como en la Asamblea General, los países latinoamericanos muestran una mayor independencia frente al hegemón. ${ }^{14}$ Además, las diferencias entre la AP y el Mercosur se difuminan en este foro internacional (figura 4).

Figura 4. Promedio de coincidencia de votos de la AP y el Mercosur con EE. UU. en la Asamblea General de la ONU

60

50

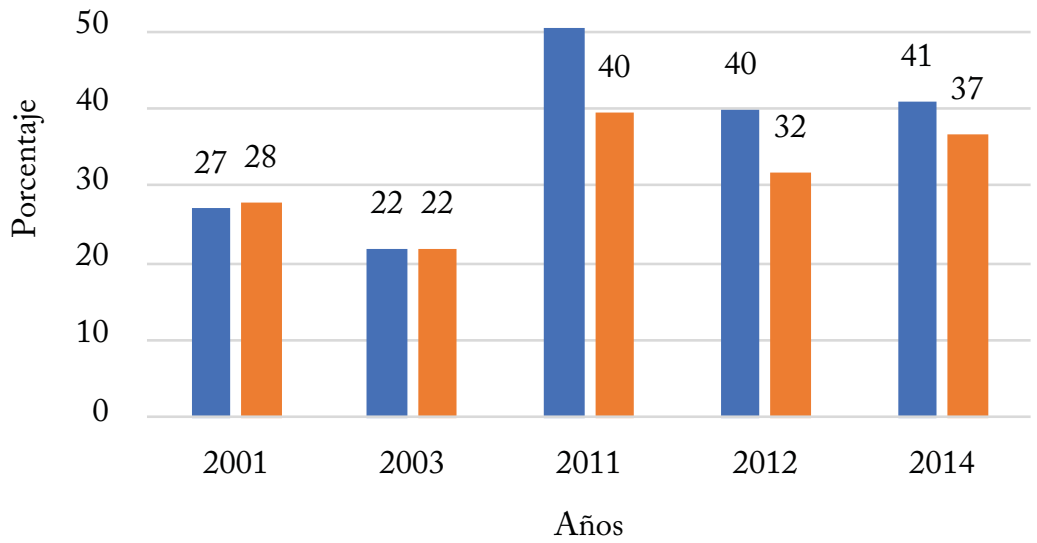

Alianza del Pacífico Mercosur ampliado

Fuente: elaborado con base en datos del Departamento de Estado de EE. UU.

14 En la Asamblea General de la ONU es habitual que los países latinoamericanos se posicionen de manera común, por ejemplo, frente a reclamos históricos como el cese del embargo a Cuba. En la Asamblea General prevalece un comportamiento regional y no subregional. 


\section{Conclusiones}

Nuestra investigación encuentra que la identificación con ideas económicas liberales coincide con una convergencia ideológica en términos de seguridad internacional y posiciones comunes en el CSNU. Así, la evidencia nos sugiere que existe una correlación entre la identidad liberal y el pensamiento de seguridad. En efecto, constatamos la activación de discursos y comportamientos comunes que casi siempre son de alineación con EE. UU. Sin duda, existen pequeños matices que diferencian a cada país de la AP. Por ejemplo, Chile y Perú se definen con mayor frecuencia bajo los marcos interpretativos del liberalismo económico que el resto. Además, Colombia fue el único que en 2003 apoyó la intervención de EE. UU. en Irak. No obstante, tales variaciones no ponen en duda el alineamiento colectivo mostrado frente a EE. UU.

Por otro lado, el rastreo del proceso histórico de cooperación en seguridad nos enseñó las razones por las que los países de la AP demuestran posiciones comunes en los foros analizados. A pesar de que cada uno proviene de trayectorias históricas diferentes, tienen en común coyunturas críticas en las que han respaldado la hegemonía estadounidense. Los cuatro países de la AP decidieron consentir la hegemonía de EE. UU. a inicios del siglo XXI como un medio para combatir amenazas internas o lograr un mejor posicionamiento de sus sistemas de defensa. Colombia, México y Perú recibieron réditos materiales de EE. UU. en términos de asistencia para mitigar sus problemas internos, mientras que Chile se diferencia por tener un enfoque de seguridad más convencional.

A partir del análisis de las ideas comunes en la AP también puede afirmarse que la identificación con valores liberales va de la mano con el respaldo de la actuación estadounidense en el ámbito de la seguridad. Entonces, las ideas económicas y de seguridad que guían la política exterior en los países de la AP no deben observarse desde ámbitos de acción diferenciados e independientes, sino que se entretejen y configuran en un todo que se articula con los intereses particulares de cada Estado. 


\section{I Javier Ernesto Ramírez Bullón - Alexandra Pérez Jiménez - Reynell Badillo Sarmiento}

Por último, la investigación resuena con algunos postulados clásicos de la política exterior latinoamericana, en la medida que constata la existencia de rasgos de aquiescencia en las relaciones de seguridad con la potencia hegemónica. Lo llamativo es que ese comportamiento se evidencia al observar los discursos formales de seguridad y las ideas económicas. Por lo tanto, la constitución de las relaciones de alineamiento de los países de la AP no difiere radicalmente de la gran estrategia de "dependencia nacional". No obstante, existe un punto de divergencia fundamental: observamos la realidad de alineamiento como resultado de trayectorias dependientes que pueden surgir de coyunturas críticas. En ese sentido, no proponemos un horizonte normativo sobre cuál es la mejor estrategia de política exterior ni clasificamos a una decisión como más beneficiosa que otra, ya que ello requeriría una evaluación de los beneficios relativos obtenidos de la alineación. En cambio, mostramos el alineamiento como una interacción histórica dinámica, de naturaleza material e ideológica, que está intervenida por factores internos que pueden cambiar.

La AP, tradicionalmente, ha sido objeto de análisis de los estudios de regionalismo económico. De modo que, a menudo, las indagaciones sobre este esquema de integración se han concentrado en explorar, sobre todo, variables económicas y políticas. En contraste, los trabajos de regionalismo de seguridad han omitido a la AP al momento de plantear y abordar sus problemas de investigación, debido a que su estructura normativa y discursiva no incorpora explícitamente ningún componente de seguridad. Este artículo constituye un esfuerzo por revalorar estos preceptos. El regionalismo económico y el de seguridad son dos esferas que pueden llegar a traslaparse, como lo ha demostrado esta investigación. De hecho, los proyectos económicos regionales pueden tener una dimensión implícita de seguridad. He aquí el puente entre los dos regionalismos: en el caso de la AP, las concepciones de seguridad de sus miembros se encuentran estrechamente vinculadas a un paquete de valores liberales sobre el que se erigió, en primer lugar, el modelo de integración. 
Esta investigación se plantea desde el realismo constructivista lo que explica nuestras elecciones metodológicas. Partimos de la idea de que el alineamiento de los países está determinado conjuntamente por los vínculos materiales que se han construido a partir de sus posiciones relativas en el sistema internacional — por lo que observamos las trayectorias históricas de cooperación y asistencia militar y policial—y de las ideas interiorizadas dentro de las EPE — por lo que realizamos un análisis temático de los discursos y los libros blancos de seguridad y defensa- De esta manera, reconocemos la asimetría de poder que pregonaría el realismo, pero también la forma en que la interpretación conjunta de conceptos de seguridad y la confluencia de las ideas entre la EPE son también parte de esa alineación. El realismo constructivista, entonces, resulta útil para no reducir la alineación únicamente a una subordinación y reconocer el rol de los discursos en las decisiones de la política exterior.

En definitiva, las ideas, incluyendo las de carácter económico, se sostienen en un arreglo de poder material. En el caso de algunos países de América Latina pareciese que, en primer lugar, hubo un alineamiento en seguridad con EE. UU. y, luego, en temas económicos. Con esta investigación hemos encontrado que el proyecto de la AP se fundamenta no solo una identidad colectiva en el plano económico y político, sino también en el ámbito de la seguridad internacional. Estos hallazgos retratan a la AP como un caso de regionalismo hegemónico, ${ }^{15}$ en el sentido que se trata de un bloque que proyecta el poder sistémico de EE. UU. no solo en términos económicos, sino políticos y de seguridad. Tales consideraciones podrían ser comprobadas en una indagación ulterior.

\footnotetext{
15 El regionalismo hegemónico enfatiza que las regiones son vulnerables a la intervención del hegemón estadounidense (Katzenstein, 1993). Este planteamiento, al ser aplicado al contexto latinoamericano, indica que la AP representa una respuesta de alineamiento a las presiones sistémicas del orden internacional liberal (Ayala \& Ramírez, 2016, p.12).
} 


\section{I Javier Ernesto Ramírez Bullón - Alexandra Pérez Jiménez - \\ Reynell Badillo Sarmiento}

\section{Agradecimientos}

Los autores agradecen a Víctor Mijares, profesor asistente del Departamento de Ciencia Política de la Universidad de los Andes (Bogotá), por las recomendaciones realizadas en el transcurso de esta investigación.

\section{Referencias}

Adins Vanbiervliet, S. (2019). El Perú frente a las nuevas configuraciones de seguridad regional y global. En S. Namihas (Ed.), La región frente a los cambios globales en materia de seguridad (pp. 175-211). IDEI-PUCP/ Konrad Adenauer Stiftung.

Agüero, F. (2005). El acuerdo de libre comercio Chile-Estados Unidos. Colombia Internacional, (61), 50-62.

Alburquerque, G. (2017). No alineamiento, tercermundismo y seguridad en Perú: La política exterior del gobierno de Juan Velasco Alvarado (19681980). América Latina Hoy, 75(0), 149-166. https:/ / doi.org/10.14201/ alh201775149166

Alcalde Cardoza, J., \& Romero Sommer, G. (2014). Alineamiento y desafio: la política exterior peruana en los gobiernos de Odría y Velasco. Fondo editorial de la Pontificia Universidad Católica del Perú.

Alhojailan, M. I. (2012). Thematic analysis: A critical review of its process and evaluation. West East Journal of Social Sciences, 1(1), 39-47.

Ardila, M. (2015). La AP y su importancia geoestratégica. Pensamiento Propio, 20(42), 243-262.

Ayala Castiblanco, L. V., \& Ramírez Bullón, J. E. (2016). El rol de China en el proyecto de un orden regional sudamericano. Revista Andina de Estudios Políticos, 6(2), 5-28.

Ayala Castiblanco, L. V., \& Ramírez Bullón, J. E. (2017). Fuerzas sistémicas en la construcción del orden regional sudamericano: El rol de la hegemonía estadounidense. Politai, 8(14), 62-101.

Barkin, J. (2004). Realist constructivism and realist-constructivisms. International Studies Review, 6(2), 348-352. https://doi.org/10.1111/j.15219488.2004.419_6.x

Barkin, J. S. (2010). Realist constructivism. Cambridge University Press. 
Barreda, P. (2014). La cooperación bilateral México-Estados Unidos contra la delincuencia organizada trasnacional en el marco de la Iniciativa Mérida. Revista IUS, 8(34), 42-60.

Becerra, L. (2013). Hacia un marco constructivista realista para el análisis de las relaciones internacionales desde las periferias. Colombia Internacional, 78(2), 79-126.

Benítez, R., \& Aguayo, S. (2016). Cooperación, seguridad y defensa: México, Estados Unidos y América Latina. En R. Benítez, \& S. Aguayo (Eds.), Atlas de la seguridad y la defensa de México 2016 (pp. 425-458). Instituto Belisario Domínguez del Senado de la República.

Benítez, R., \& Rodríguez, C. (2006). Seguridad y fronteras en Norteamérica. Del TLCAN a la ASPAN. Frontera Norte, 18(35), 7-28.

Bernal, J., \& Tickner, A. (2017). Imaginario de política exterior y proamericanismo en Colombia. En A. Tickner, \& S. Bitar (Eds.), Nuevos enfoques para el estudio de las relaciones internacionales de Colombia (pp. 3-38). Universidad de los Andes.

Bitar, S. (2016). US military bases, quasi-bases, and domestic politics in Latin America. Springer.

Borda, S. (2007). La internacionalización del conflicto armado después del 11 de septiembre: ¿La ejecución de una estrategia diplomática hábil o la simple ocurrencia de lo inevitable? Colombia Internacional, 65(1), 66-89.

Brands, H. (2008). Third world politics in an age of global turmoil: The Latin American challenge to US and western hegemony, 1965-1975. Diplomatic History, 32(1), 105-138. https://doi.org/10.1111/j.14677709.2007.00669.x

Brands, H. (2010). The United States and the Peruvian challenge, 1968-1975. Diplomacy \& Statecraft, 21(3), 471-490. https://doi.org/10.1080/0959 2296.2010.508418

Burgué, P., Pato, P., \& Díaz, Á. (2010). Comunicación sostenible. LID Editorial. Bywaters, C. (2014). El «NO» de Ricardo Lagos a la invasión de Irak en 2003: el proceso de toma de decisiones de política exterior en Chile. Estudios internacionales, 46(177), 65-88. https:/ /dx.doi.org/10.5354/07193769.2014.30869

Chacón, S. (2000). La negociación del acuerdo militar entre México y Estados Unidos, 1940-1942. Foro Internacional, 40(2), 307-344. 


\section{I Javier Ernesto Ramírez Bullón - Alexandra Pérez Jiménez - \\ Reynell Badillo Sarmiento}

Chile, Ministerio de Defensa Nacional. (2018). Chile y Estados Unidos firman acuerdo de cooperación en ciberdefensa. https://www.defensa.cl/noticias/ chile-y-ee-uu-firman-acuerdo-de-cooperacion-en-ciberdefensa/

Echandía, C. (2000). El conflicto armado colombiano en los años noventa: cambios en las estrategias y efectos económicos. Colombia Internacional, (49-50), 117-134. https://doi.org/10.7440/colombiaint49-50.2000.06 Estados Unidos, Embajada en Chile. (2019). Politica e historia. https:// cl.usembassy.gov/es/our-relationship-es/policy-history-es/

Friedman, M. P., \& Long, T. (2015). Soft balancing in the Americas: Latin American opposition to US intervention, 1898-1936. International Security, 40(1), 120-156.

Gabriel, C., Jiménez, J., \& McDonald, L. (2006). Hacia las “fronteras inteligentes" norteamericanas: ¿convergencia o divergencia en las políticas de control de fronteras? Foro Internacional, 43(3), 549-579.

Galeano, H., Badillo, R., \& Rodríguez, M. (2019). Evolución de la política exterior de Colombia en el periodo 2002-2018. OASIS, (29), 57-79. https://doi.org/10.18601/16577558.n29.04

González, R., Galeano, H., \& Trejos, L. (2015). Estados Unidos en la política exterior colombiana: ¿aliado incondicional? Económicas CUC, 36(1), 43-56. http://dx.doi.org/10.17981/econcuc.36.1.2015.23

Guevara, J. (2015). El Plan Colombia o el desarrollo como seguridad. Revista de Sociología, 38(1), 63-82. http:/ /dx.doi.org/10.15446/rcs.v38n1.53264

Hopf, T. (2002). Social construction of international politics: Identities \& foreign policies, Moscow, 1955 and 1999. Cornell University Press.

Hurrell, A. (2013). Narratives of emergence: Rising powers and the end of the Third World? Brazilian Journal of Political Economy, 33(2), 203-221.

Hurtado, S. (2016). Chile y Estados Unidos, 1964-1973. Una nueva mirada. Nuevo Mundo Mundos Nuevos, 16. https://doi.org/10.4000/nuevomundo.69698

Ikenberry, J. (2010). The liberal international order and its discontents. $M i$ llennium, 38(3), 509-521. https://doi.org/10.1177/0305829810366477

Infodefensa.com. (2016, diciembre 22). China dona 7,2 millones de dólares en equipos militares a las FF. AA. de Perú. http://www.infodefensa.com/ latam/2016/12/22/noticia-china-ministerio-defensa-siete-millonesdolares-equipos-militares.html 
Johnson, P. (1986). The subordinate states and their strategies. En J. Triska (Ed.), Dominant powers and subordinate states: The United States in Latin America and the Soviet Union in eastern Europe (pp. 285-309). Duke University Press.

Katzenstein, P., \& Sil, R. (2008). Eclectic theorizing in the study and practice of international relations. En C. Reus-Smit., \& D. Snidal (Eds.), The Oxford Handbook of International Relations (pp. 109-130). https:// doi.org/10.1093/oxfordhb/9780199219322.003.0006

Katzenstein, P. (1993). World of regions: America, Europe, and East Asia. Indiana Journal of Global Legal Studies, 1, 65-82.

van Klaveren, A. (2014). El análisis de la política exterior: Una visión desde América Latina. En T. Legler, A. Santa Cruz, \& L. Zamudio (Eds.), Introducción a las relaciones internacionales: América Latina y la politica global (pp. 96-109). Oxford University Press.

Kubalkova, V. (2001). Foreign policy in a constructed world. Routledge.

Lindsay-Poland, J. 2009. us military bases in Latin America and the Caribbean. En C. Lutz (Ed.), The bases of empire: The global struggle against US military Posts (pp. 71-96). NYU Press.

Luzzani, T. (2012). Territorios vigilados: Cómo opera la red de bases militares norteamericanas en Sudamérica. Penguin Random House, Grupo Editorial Argentina.

Marchini, G. (2019). La Alianza del Pacífico a ocho años de su creación. Balance crítico y perspectivas. Anuario Latinoamericano Ciencias Políticas y Relaciones Internacionales, (7), 75-109.

Meyer, P. (2014). Chile: Political and economic conditions and US relations. Congressional Research Service.

Mijares, V. (2020). Filling the structural gap: Geopolitical links explaining the South American defense council. Colombia Internacional, (101), 3-28. https://doi.org/10.7440/colombiaint101.2020.01

Monroy, M. C. (2014). Tomadores bumanos de decisión Plan Colombia: una estratégica politica exterior de Estados Unidos. Universidad Sergio Arboleda.

Monroy, M. C., \& Sánchez, F. (2017). Foreign policy analysis and the making of Plan Colombia. Global Society, 31(2), 1-27.

Nolte, D., \& Wehner, L. (2013). The Pacific Alliance casts its cloud over Latin America. GIGA Focus, 8. https://www.giga-hamburg.de/en/ system/files/publications/gf_international_1308.pdf 


\section{I Javier Ernesto Ramírez Bullón - Alexandra Pérez Jiménez - \\ Reynell Badillo SaRmiento}

Olano Alor, A. (2013). Perú: Evaluación de 10 años de una política de seguridad y defensa. Criterios, 6(1), 59-76.

Olano Alor, A. (2017). Regionalismo abierto y nuevo multilateralismo: El Perú en la Alianza del Pacífico. En M. Ardila (Ed.), ¿Nuevo multilateralismo en América Latina? Concepciones y actores en pugna (pp. 237-256). Universidad Externado de Colombia.

Organización para la Cooperación y el Desarrollo Económico — OCDE(2018). OECD.Stat. Aid (ODA) commitments to countries and region [DAC3a]. https://stats.oecd.org

Paredes, A. (2004). La Operación Cóndor y la guerra fría. Universum, 19(1), 122-137. https://dx.doi.org/10.4067/S0718-23762004000100007

Pastrana Buelvas, E., \& Castro, R. (2019). La ideología sedimentada de la AP. En E. Tremolada Álvarez (Ed.), Gobernanza, cooperación internacionaly valores democráticos comunes (pp. 387-430). Universidad Externado de Colombia.

Pastrana Buelvas y Castro (2020). Auge y estancamiento de la Alianza del Pacífico. Análisis Carolina, (7), 1-20.

Pastrana, E., \& Gehring, H. (2014). Alianza del Pacífico: mitos y realidades. Universidad Santiago de Cali.

Pierson, P., \& Skocpol, T. (2008). El institucionalismo histórico en la ciencia política contemporánea. Revista Uruguaya de Ciencia Política, 17(1), 7-38.

Ramírez Bullón, J. E. (2018). La legitimación del libre comercio en la política exterior peruana: Del TLC con Estados Unidos al surgimiento de la AP. (Tesis de pregrado, Pontificia Universidad Católica del Perú). http://tesis.pucp. edu.pe/repositorio//handle/123456789/12225

Ramírez, S. (2004). Intervención en conflictos internos. El caso colombiano 19942003. Universidad Nacional de Colombia-IEPRI.

Riggirozzi, P., \& Tussie, D. (2012). The rise of post-hegemonic regionalism in Latin America. En P. Riggirozzi, \& D. Tussie (Eds.), The rise of post-hegemonic regionalism: The case of Latin America (pp. 1-16). Springer Netherlands. https:/ /doi.org/10.1007/978-94-007-2694-9_1

Riorda, M. (2008). "Gobierno bien, pero comunicó mal”: Análisis de las rutinas de la comunicación gubernamental. Revista del CLAD Reforma y Democracia, (40).

Rojas, D. (2006). Los Estados Unidos y la guerra en Colombia. Grupo Editorial Norma. 
Russell, R., \& Tokatlian, J. G. (2002). De la autonomía antagónica a la autonomía relacional: Una mirada teórica desde el Cono Sur. Perfiles Latinoamericanos, 10(21), 159-194.

Russell, R., \& Tokatlian, J. G. (2009). Modelos de política exterior y opciones estratégicas: El caso de América Latina frente a Estados Unidos. Revista CIDOB d'Afers Internacionals, 85-86, 211-249.

Russell, R., \& Tokatlian, J. G. (2011). Beyond orthodoxy: Asserting Latin America's new strategic options toward the United States. Latin American Politics and Society, 53(4), 127-146.

Russell, R., \& Tokatlian, J. G. (2013). América Latina y su gran estrategia: Entre la aquiescencia y la autonomía. Revista CIDOB d'Afers Internacionals, 104, 157-180.

Sanahuja, J. (2016). Regionalismo e integración en América Latina: De la fractura Atlántico-Pacífico a los retos de una globalización en crisis. Pensamiento Propio, 21(44), 29-75.

Schenoni, L., \& Escudé, C. (2016). Peripheral realism revisited. Revista Brasileira de Politica Internacional, 59(1), 1-18. https:/ / doi.org/10.1590/00347329201600102

Strange, S. (1996). The retreat of the state: The diffusion of power in the world economy. Cambridge University Press.

Tickner, A. (2007). Intervención por invitación: Claves de la política exterior colombiana y de sus debilidades principales. Colombia Internacional, 65(2), 90-111.

US Agency for International Development —USAID_- (2018). US overseas loans and grants: Obligations and loan authorizations, July 1, 1945-September 30. https:/ / explorer.usaid.gov/reports.html

Valdivieso, C. (2015). Política externa de Chile 2006-2014: una comparación entre los periodos de Bachelet y Piñeira. Ponencia presentada en el $I$ Encuentro Internacional de Politica Externa Latinoamericana. Universidade Federal da Integração Latino-Americana (UNILA).

Vargas Alzate, L. F. (2019). La Alianza del Pacífico como elemento catalizador para la cooperación: una revisión desde la óptica del Sur Global. OASIS: Observatorio de Análisis de los Sistemas Internacionales, (29), 175-196.

Waltz, K. (1979). Theory of international politics. Waveland Press.

Weiss, T., \& Thakur, R. (2010). Global governance and the UN: An unfinished journey. Indiana University Press. 
40 / Javier Ernesto Ramírez Bullón - Alexandra Pérez Jiménez -

Reynell Badillo Sarmiento

Wilhelmy, M., \& Durán, R. (2003). Los principales rasgos de la política exterior chilena entre 1973 y el 2000. Revista de ciencia politica (Santiago), 23(2), 273-286. https:/ / dx.doi.org/10.4067/S0718-090X2003000200014

Wendt, A. (1999). Social theory of international politics. Cambridge University Press. 